Article

\title{
Importance of B Lymphocytes and the IgG-Binding Protein Sbi in Staphylococcus aureus Skin Infection
}

\author{
Fan Zhao ${ }^{1}$, Anita S. Chong ${ }^{2}$ and Christopher P. Montgomery ${ }^{1, *}$ \\ 1 Department of Pediatrics, The University of Chicago, Knapp Center for Biomedical Discovery 5124, \\ 900 E. 57th Street, Chicago, IL 60637, USA; fzhao@peds.bsd.uchicago.edu \\ 2 Department of Surgery, The University of Chicago, Chicago, IL 60637; USA; \\ achong@surgery.bsd.uchicago.edu \\ * Correspondence: cmontgomery@bsd.uchicago.edu; Tel.: +1-773-834-0897
}

Academic Editor: Rachel McLoughlin

Received: 1 September 2015; Accepted: 21 January 2016; Published: 27 January 2016

\begin{abstract}
Recurrent Staphylococcus aureus infections are common, suggesting that immunity elicited by these infections is not protective. We previously reported that $S$. aureus skin infection (SSTI) elicited antibody-mediated immunity against secondary SSTI in BALB/c mice. In this study, we investigated the role of humoral immunity and the IgG-binding proteins Sbi and SpA in S. aureus SSTI. We found that B lymphocyte-deficient $\mu \mathrm{MT}$ mice were highly susceptible to infection, compared with congenic BALB/c mice. Importantly, transfer of immune serum protected $\mu \mathrm{MT}$ mice, demonstrating an appropriate response to protective antibody. We found that deletion of $s b i$, but not spa, impaired virulence, as assessed by skin lesion severity, and that Sbi-mediated virulence required B lymphocytes/antibody. Furthermore, neither Sbi nor SpA impaired the elicited antibody response or protection against secondary SSTI. Taken together, these findings highlight a B lymphocyte/antibody-dependent role of Sbi in the pathogenesis of S. aureus SSTI, and demonstrate that neither Sbi nor SpA interfered with elicited antibody-mediated immunity.
\end{abstract}

Keywords: MRSA; skin infection; Sbi; protein A; Staphylococcus aureus; antibody; protective immunity

\section{Introduction}

Staphylococcus aureus causes a wide range of infectious syndromes, including asymptomatic colonization, relatively minor skin and soft tissue infections (SSTI), and more severe infections, such as complicated SSTI, pneumonia, bone and joint infections, and sepsis [1]. S. aureus infections have become epidemic in the United States, highlighted by the emergence of the community-associated methicillin-resistant genotype USA300 [1]. Recurrent infections are common, suggesting that S. aureus infections frequently fail to elicit immunity that protects against subsequent infections [2], and the adaptive immune mechanisms that protect against recurrent $S$. aureus infection remain elusive.

$\mathrm{T}$ lymphocyte mediated-immunity is clearly important in defense against $S$. aureus infections, because patients with Hyper IgE Syndrome, who have defects in pathways controlling Th17/IL-17A mediated immunity, have high rates of recurrent S. aureus pneumonia and SSTI [3]. In addition, patients with poorly controlled HIV infection and low CD4+ T cell counts are at high risk for recurrent S. aureus SSTI, although there are other factors besides T cell lymphopenia that could contribute to this observation [4,5]. In contrast, a role for humoral immune defects in predisposing to recurrent S. aureus infections remains less well defined. Increased frequencies of SSTI and S. aureus infections in patients with the inherited antibody deficiency X-linked agammaglobulinemia or with the common variable immunodeficiency have been reported [6,7], although whether this association is due specifically to the inability to produce protective antibodies remains unclear. Additionally, confounding the 
notion that antibodies play a critical role in the protection against SSTI, are the observations that anti-staphylococcal antibodies are almost universally detected in the healthy human population yet a portion still develop SSTIs [8-10].

The genome of $S$. aureus encodes for several proteins that bind IgG, suggesting that $S$. aureus has evolved mechanisms to inhibit and/or interfere with antibody-mediated immunity. For example, staphylococcal protein $\mathrm{A}(\mathrm{SpA})$ acts as a $\mathrm{B}$ cell superantigen by binding to the $\mathrm{V}_{\mathrm{H}} 3$ Fab portion of the $\mathrm{B}$ cell receptor and triggering apoptosis of $B$ cells [11]. A consequence of this activity is the ability of SpA to inhibit antibody responses against other $S$. aureus antigens, thus preventing the development of protective antibody-mediated immunity $[12,13]$. Consistent with this hypothesis, intravenous infection with a SpA deletion mutant elicited more robust protective antibody responses to non-SpA antigens, compared with an isogenic wild-type isolate [14]. Pauli et al. recently reported another mechanism of SpA-mediated immune evasion, whereby the superantigenic activity of SpA leads to an antibody response that is largely focused on SpA and limits responses to other $S$. aureus virulence factors that confer protection [15]. These findings suggest that the mechanisms by which SpA prevent protective immune responses may be complex and multifactorial.

While SpA has been shown to be an important virulence factor in multiple mouse models of S. aureus pneumonia and bloodstream infection [16-18], the importance of another IgG binding protein, called second binder of IgG (Sbi) is less clear $[19,20]$. SpA binds to the Fc $\gamma$ domain of IgG thereby preventing the ability of IgG to bind to host Fc $\gamma$ Rs [21]. In contrast, Sbi has two Ig-binding domains and two domains that bind to complement component $\mathrm{C} 3$. A consequence of Sbi binding to IgG and C3 is the futile consumption of $\mathrm{C} 3$, a novel strategy for immune evasion that may involve the recruitment of plasmin to degrade recruited complement components [22-24].

We recently reported a mouse model of recurrent $S$. aureus SSTI, in which primary infection protects BALB/C, but not C57BL/6, mice against secondary infection [25]. This protection was dependent on both antibody-mediated immunity and the Th17/IL-17A pathway, and was inhibited by the Th1/IFN $\gamma$ pathway. Because of the importance of antibody-mediated immunity, we hypothesized that B lymphocytes play an important role in innate and adaptive defenses in this model. We also hypothesized that SpA and/or Sbi would be important in virulence in primary SSTI and would interfere with the development of protective immunity. We report herein that B lymphocyte deficient $\mu \mathrm{MT}$ mice have increased susceptibility to primary S. aureus SSTI, but retain the ability to respond to adoptively transferred protective antibody. We also observed a role for Sbi, but not SpA, in the virulence of primary S. aureus SSTI. The importance of Sbi in the virulence of primary SSTI was dependent on B lymphocytes and/or antibody, because there was no effect of Sbi on virulence in $\mu \mathrm{MT}$ mice. Surprisingly, neither Sbi nor SpA inhibited protective immunity or antibody responses. Taken together, these findings highlight a B cell/antibody dependent role of Sbi in virulence, and unexpectedly demonstrate that these IgG-binding proteins do not interfere with protective immunity in this model of recurrent $S$. aureus SSTI.

\section{Results}

\subsection{Increased Susceptibility of B Cell Deficient Mice to S. aureus SSTI}

To assess the role of B cells and/or antibodies in the defense against primary S. aureus SSTI (dermonecrosis), age-matched BALB/c and B cell deficient ( $\mu \mathrm{MT}) \mathrm{BALB} / \mathrm{c}$ mice were inoculated subcutaneously with $1.5 \times 10^{7} \mathrm{CFU}$ S. aureus isolate 923 . Subcutaneous inoculation of $\mu \mathrm{MT}$ mice resulted in significantly larger dermonecrotic lesions, compared with BALB/c mice $(p<0.01$, Figure $1 \mathrm{~A})$. The larger lesions observed in $\mu \mathrm{MT}$ mice were associated with approximately 10 -fold greater numbers of bacteria recovered from the lesions $3 \mathrm{~d}$ after infection $(p<0.05$, Figure 1B), as well as higher levels of the inflammatory chemokine CXCL-1 ( $p<0.01$, Figure 1C), but not IL-17A ( $p=0.15$, Figure 1D). To determine whether $\mu \mathrm{MT}$ mice retained the ability to respond to protective antibody, serum from naïve or previously infected BALB/c mice was adoptively transferred to naïve $\mu \mathrm{MT}$ mice prior to 
SSTI. Transfer of immune BALB/c serum resulted in significantly smaller skin lesions, compared with recipients of PBS or serum from naïve mice $(p<0.01$, Figure 1E). There were also fewer bacteria recovered from the lesions of $\mu \mathrm{MT}$ mice that received immune serum $(p<0.05$, Figure 1F). The finding that there were fewer bacteria recovered from the lesions of WT mice, compared with $\mu \mathrm{MT}$ mice, together with our previous report of decreased numbers of bacteria recovered from the lesions of BALB/c mice following secondary SSTI, compared with primary SSTI [25], suggest that antibody-mediated immunity results in enhanced bacterial clearance from dermonecrotic skin lesions. Taken together, these findings suggested that B cells and the antibodies they produce play a role in defense against $S$. aureus SSTI by limiting bacterial growth and local production of the neutrophil chemoattractant CXCL-1, but $\mu \mathrm{MT}$ mice retained the ability to respond to adoptively transferred protective antibody.
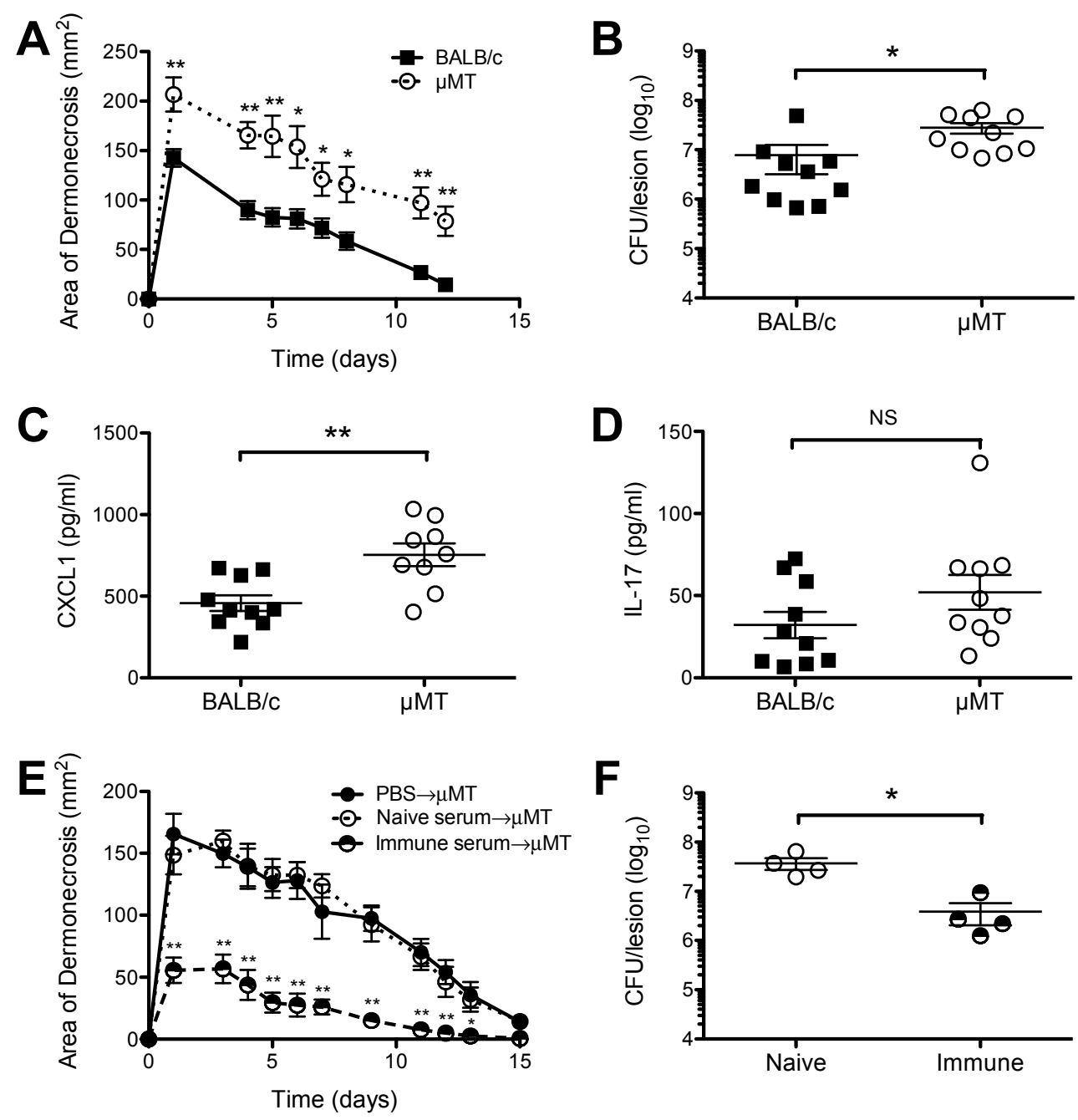

Figure 1. B cell deficient $\mu \mathrm{MT}$ mice had increased susceptibility to $S$. aureus SSTI, but responded to protective antibody. (A) $\mu \mathrm{MT}$ mice had larger lesions, compared with BALB/c mice, after primary S. aureus SSTI. The skin lesions of $\mu \mathrm{MT}$ mice had greater numbers of bacteria (B) and higher levels of CXCL1 (C) 3 d after infection, compared with BALB/c mice; (D) There were no significant differences in the levels of IL-17A in the skin lesions of BALB/c and $\mu \mathrm{MT}$ mice $3 \mathrm{~d}$ after infection; (E) Adoptive transfer of serum from previously infected BALB/c mice protected $\mu \mathrm{MT}$ mice, compared with transfer of serum from naive BALB/c mice or PBS; (F) There were fewer bacteria recovered from the lesions of $\mu \mathrm{MT}$ after transfer of immune BALB/c serum, compared with naïve serum. Results are presented as the means \pm SEM ( $n=4-10$ mice/group). All experiments were performed at least twice. * indicates $p<0.05,{ }^{* *}$ indicates $p<0.01$, NS indicates not significant. 


\subsection{A Role for Sbi, but not SpA, in the Pathogenesis of SSTI Caused by USA300}

The increased susceptibility of $\mu \mathrm{MT}$ mice to $S$. aureus SSTI led us to hypothesize that the IgG binding proteins Sbi and/or SpA would promote the virulence of S. aureus SSTI. Therefore, the isogenic deletion mutants $\Delta s b i, \Delta s p a$, or $\Delta s b i \Delta s p a$ were constructed in strain 923 . There were no significant differences in the growth rate of the strains (data not shown). Deletion was confirmed by semiquantitative RT-PCR (Figure 2). Subcutaneous inoculation of BALB/c mice with $\Delta s b i \Delta s p a$ resulted in smaller lesions and a $0.8 \mathrm{log}$ reduction in the number of bacteria recovered from the lesions, compared with inoculation with the wild-type isolate (WT) $(p<0.01$, Figure 3A,B). To determine whether Sbi and/or SpA were necessary for virulence, mice were inoculated with the WT isolate, $\Delta s p a$, or $\Delta s b i$. Consistent with our hypothesis, infection with $\Delta s b i$ resulted in smaller dermonecrotic skin lesions $(p<0.01$, Figure 3C) and fewer bacteria recovered from the lesions ( $p<0.05$, Figure 3D), compared with WT. In contrast, infection with $\Delta s p a$ resulted in no significant differences in the size of skin lesions compared with WT ( $p>0.3$, Figure 3E). Furthermore, complementation of sbi into $\Delta s b i \Delta s p a$ restored virulence to that of the WT isolate $(p<0.05$ compared with $\Delta s b i \Delta s p a$, Figure 3F). However, infection with $\Delta s b i \Delta s p a / p s b i$ did not restore the number of bacteria recovered from the lesions to levels observed with the WT isolate $\left(1.6 \times 10^{7} \pm 4.0 \times 10^{6} \mathrm{CFU}\right.$ after infection with $\Delta$ sbi $\Delta$ spa; $1.0 \times 10^{7} \pm 3.9 \times 10^{6} \mathrm{CFU}$ after infection with $\Delta$ sbi $\Delta$ spa/psbi; $\left.p=0.3\right)$.

A

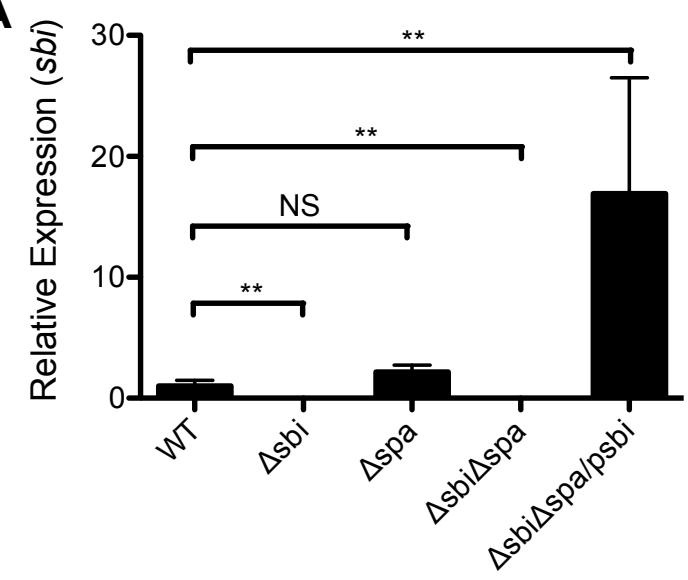

B

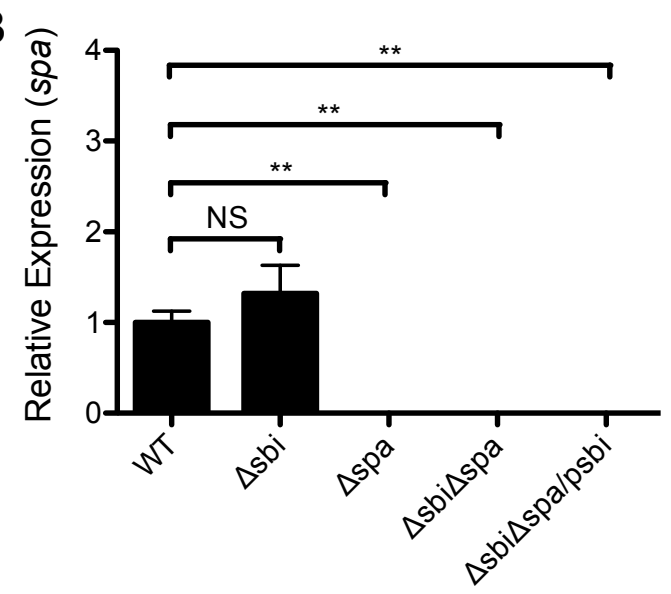

Figure 2. Expression of $s b i$ and $s p a$ in the strains used in this study. (A) Expression of $s b i$ by semi-quantitative RT-PCR in a wild-type $S$. aureus USA300 isolate (WT), isogenic sbi $(\Delta s b i)$ and spa $(\Delta s p a)$ deletion mutants, a double sbi/spa deletion mutant $(\Delta s b i \Delta s p a)$, and the double deletion mutant complemented with sbi expressed on a multi-copy plasmid ( $\Delta$ sbi $\Delta s p a / p s b i) ;(B)$ Expression of $s p a$ by semi-quantitative RT-PCR. Expression is quantified by the $\Delta \Delta \mathrm{C}_{\mathrm{T}}$ method, normalized to a housekeeping gene $(g y r B)$, and expressed relative to the WT strain. Results are presented as the means \pm SEM. All experiments were performed at least twice. ${ }^{* *}$ indicates $p<0.01$, NS indicates not significant.

Because of the antibody-binding properties of Sbi, we hypothesized that Sbi mediated virulence via interaction with antibodies. To test this, we infected $\mu \mathrm{MT}$ mice with WT or $\Delta s b i \Delta s p a$. In support of this hypothesis, there were no significant differences in the size of dermonecrotic skin lesions between $\mu \mathrm{MT}$ mice infected with 923 or $\Delta s b i \Delta s p a(p>0.3$, Figure 3G). Because the phenotypes of $\Delta s b i$ and $\Delta$ sbi $\Delta$ spa in this model are indistinguishable, we presume that the interaction with B cells and/or antibody is mediated by Sbi. Therefore, deletion of $s b i$, but not $s p a$, attenuated virulence in this model of SSTI in BALB/c mice, and B lymphocytes and/or antibodies were required for Sbi-mediated virulence. 


\subsection{Neither Sbi nor SpA Impacted Protective Immunity against Recurrent S. aureus SSTI}

Because of a demonstrated role for SpA in inhibiting the development of protective antibody responses against $S$. aureus sepsis [14], we tested the roles of Sbi and SpA in the development of protective immunity against $S$. aureus SSTI. We performed primary infection of BALB/c mice with WT, $\Delta s b i, \Delta s p a$, or $\Delta s b i \Delta s p a$, and then 8 wks later challenged with WT $S$. aureus. Infection with WT, $\Delta s b i$ $(p<0.01$, Figure 4A), $\Delta s p a(p<0.01$, Figure 4B), or $\Delta s b i \Delta s p a(p<0.01$, Figure 4C) all elicited protective immunity against secondary SSTI, suggesting that neither Sbi nor SpA affected the elicited antibody response in BALB/c mice. Furthermore, we quantified antibody levels against $\alpha$-hemolysin (Hla), an important vaccine candidate [26,27] and observed no significant differences in anti-Hla IgG titers between mice infected with WT or $\Delta s b i \Delta s p a(p>0.4$, Figure 4D).
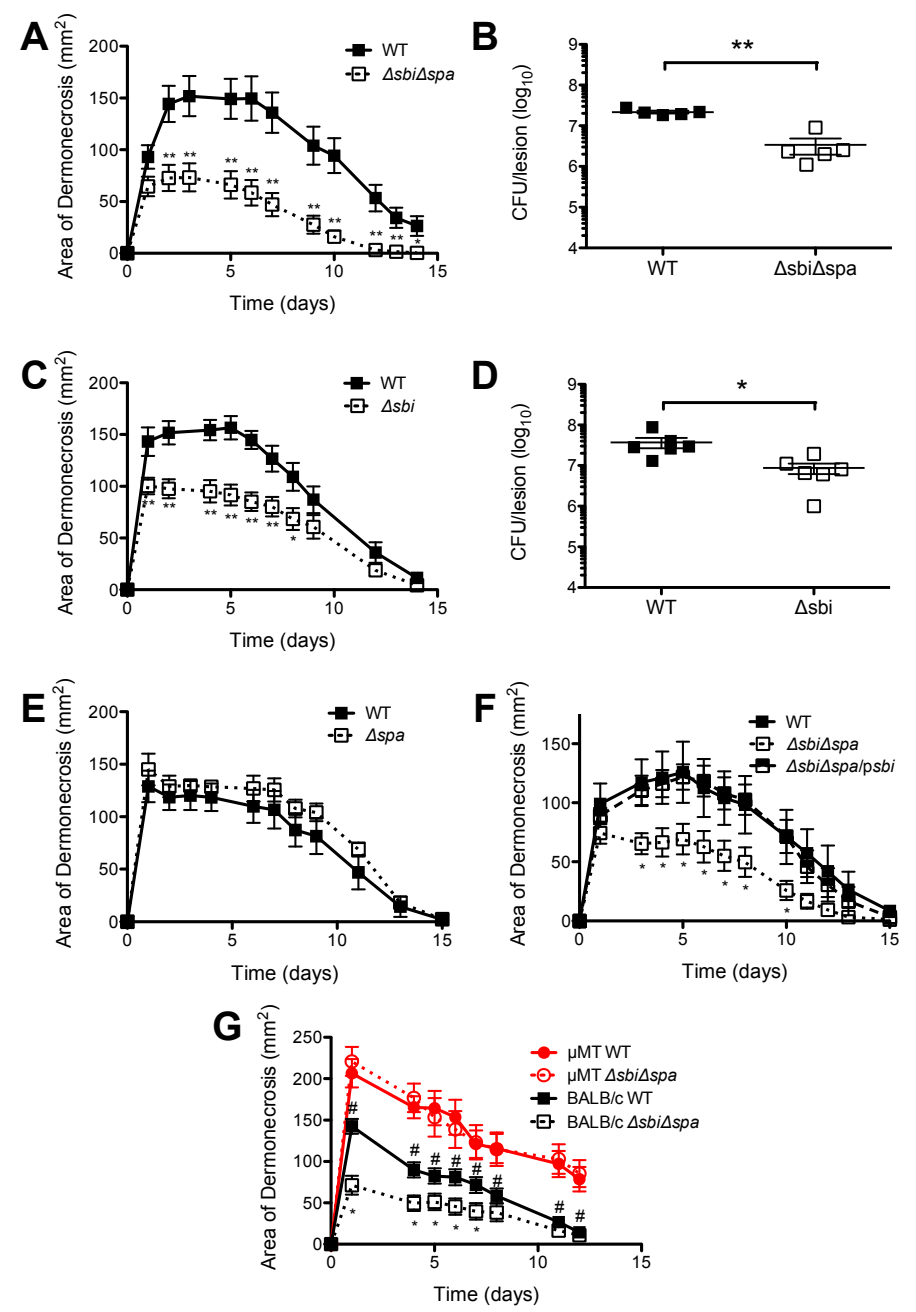

Figure 3. Sbi, but not spa, was a virulence factor in S. aureus SSTI and required B lymphocytes for virulence. Compared with infection with the wild-type USA300 isolate, infection of BALB/c mice with $\Delta$ sbi $\Delta$ spa resulted in smaller skin lesions (A) and fewer bacteria recovered from the lesions $3 \mathrm{~d}$ after infection (B); (C,D) Infection with $\Delta s b i$ also resulted in smaller skin lesions and fewer bacteria recovered from the lesions; (E) In contrast, there were no significant differences in lesion size afer infection with WT or $\Delta s p a$; (F) Complementation of $s b i$ into $\Delta s b i \Delta s p a$ restored virulence; (G) There was no difference in the size of skin lesions in $\mu \mathrm{MT}$ mice infected with the WT USA300 isolate or $\Delta s b i \Delta s p a$. Results are presented as the means $\pm \operatorname{SEM}(n=5-10$ mice/group). All experiments were performed at least twice. * indicates $p<0.05$, ${ }^{* *}$ indicates $p<0.01$; For $(\mathbf{F}),{ }^{*}$ indicates $p<0.05$ compared with BALB $/ \mathrm{c}$ $\mathrm{WT}$, \# indicates $p<0.05$ compared with $\mu \mathrm{MT}$ WT. 
We previously reported that, in contrast to BALB/c mice, primary SSTI in C57BL/6 mice failed to elicit protective antibody-mediated immunity despite eliciting a polyclonal antibody response [25]. Because SpA has been reported to interfere with the repertoire of antigen-specific antibody responses [14], we hypothesized that primary SSTI with $\Delta$ spa might be able to enhance protection in C57BL/ 6 mice. To test this, we performed primary SSTI in C57BL/ 6 mice with WT or $\Delta$ spa, followed by assessment of anti-Hla IgG and secondary infection with WT. As we observed in $\mathrm{BALB} / \mathrm{c}$ mice, there were no significant differences in the size of dermonecrotic skin lesions after primary infection with WT or $\Delta s p a(p>0.3$, Figure 5A). Furthermore, there were no significant differences in anti-Hla IgG titers of C57BL/ 6 mice after infection with WT or $\Delta s p a(p>0.4$, Figure 5B), suggesting no inhibition by SpA of potentially protective antibody responses. We also tested for the development of protective immunity. Although protection against WT SSTI in C57BL/6 mice after primary SSTI infection was considerably more modest than in BALB/c mice, we were nevertheless able to confirm that primary infection with $\Delta$ spa elicited comparable protection against secondary SSTI with WT $(p>0.3$, Figure $5 \mathrm{C})$. There were also no significant differences in protection elicited after primary infection with WT or $\Delta s b i \Delta s p a(p>0.1$, Figure 5D). Taken together, these findings suggest that neither Sbi nor SpA alter the magnitude of the antibody response to Hla and protective immunity against recurrent $S$. aureus SSTI.
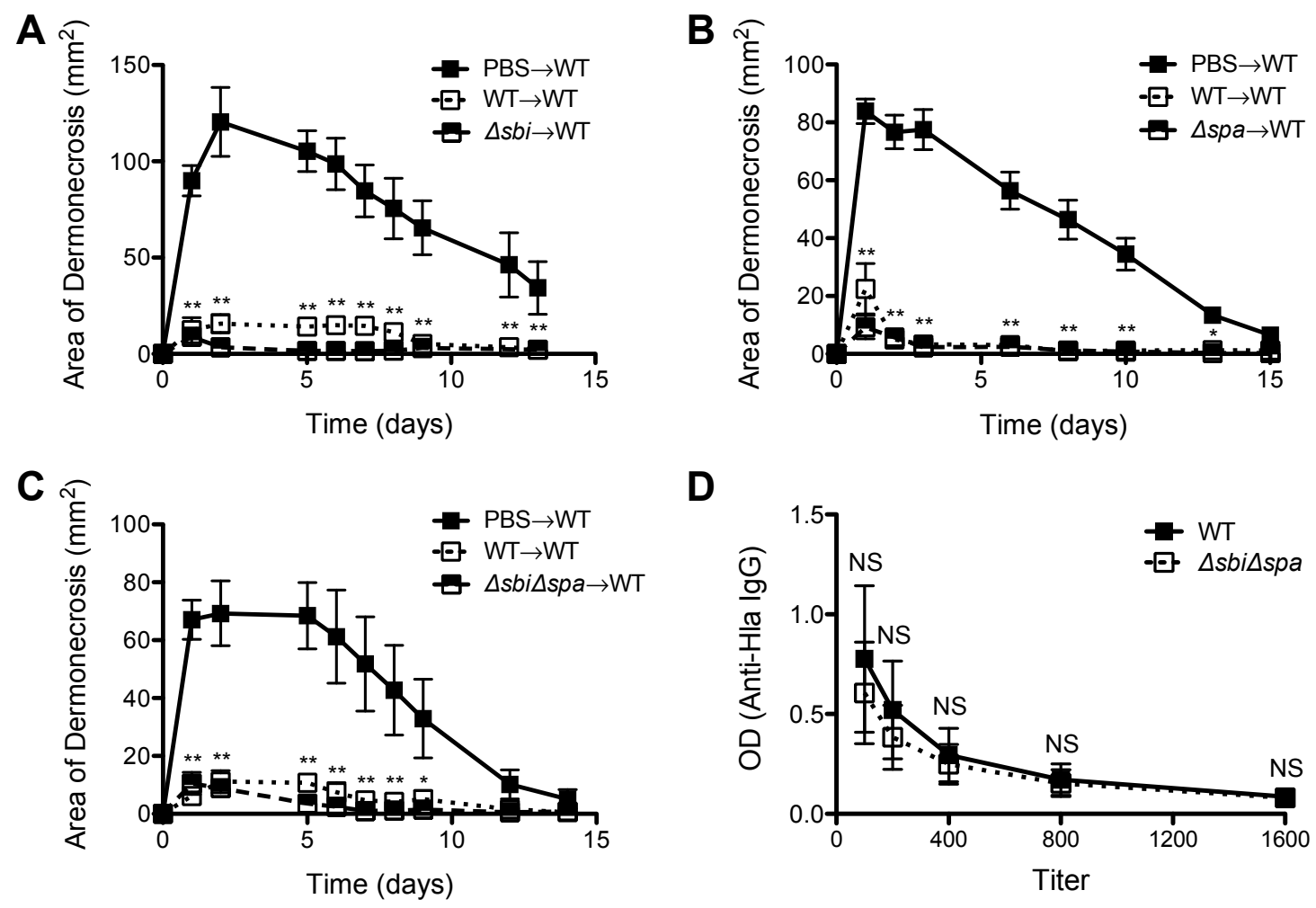

Figure 4. Expression of sbi or spa during primary S. aureus SSTI did not impact development of protective immunity in BALB/c mice. Primary SSTI with $\Delta s b i(\mathbf{A}) ; \Delta s p a(\mathbf{B})$; or $\Delta s b i \Delta s p a(\mathbf{C})$ protected $\mathrm{BALB} / \mathrm{c}$ mice equally well against secondary SSTI with the WT isolate, compared with primary SSTI with WT; (D) There were no significant differences in anti-Hla IgG titers after infection with WT or $\Delta s b i \Delta s p a$. Results are presented as the means \pm SEM ( $n=5-10$ mice/group). All experiments were performed at least twice. ${ }^{*}$ indicates $p<0.05,{ }^{* *}$ indicates $p<0.01$, NS indicates not significant. 

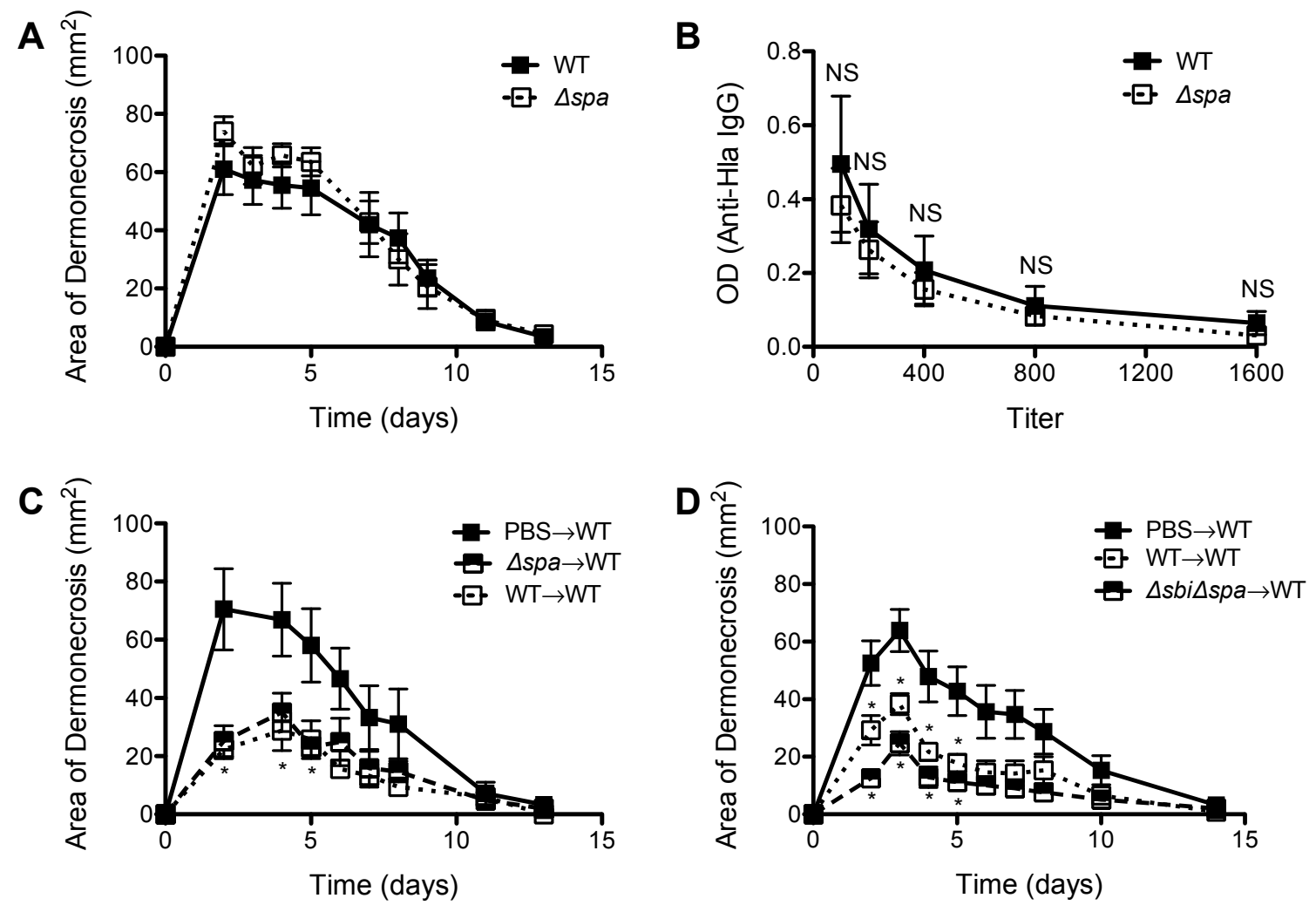

Figure 5. Expression of spa during primary SSTI did not impact protective immunity in C57BL/6 mice. (A) There were no signficant differences in the size of skin lesions after primary infection of C57BL/6 mice with WT or $\Delta s p a$; (B) There were no significant differences in anti-Hla IgG titers after infection with WT or $\Delta s p a$; (C) Primary SSTI with $\Delta$ spa did not elicit superior protection, compared with the WT isolate, against secondary SSTI with WT in C57BL/6 mice; (D) Primary SSTI with $\Delta$ sbi $\Delta$ spa did not elicit superior protection, compared with the WT isolate, against secondary SSTI with WT in C57BL/6 mice. Results are presented as the means $\pm \operatorname{SEM}(n=4-8$ mice/group). All experiments were performed at least twice. * indicates $p<0.05$ compared with PBS $\rightarrow$ WT, NS indicates not significant.

\section{Discussion}

We found that B lymphocyte deficient $\mu \mathrm{MT}$ mice were highly susceptible to $S$. aureus SSTI, with larger dermonecrotic skin lesions, more bacteria in the lesions, and higher levels of the inflammatory chemokine CXCL-1 in the lesions, compared with congenic BALB/c mice. This is in contrast with reported findings in other models of $S$. aureus infection. For example, Spellberg et al. reported similar mortality after intravenous inoculation of S. aureus in BALB/c and $\mu \mathrm{MT}$ mice [28]. Similarly, Falugi et al. observed that bloodstream infection in $\mu \mathrm{MT}$ mice resulted in fewer bacteria in the kidneys and fewer bacterial abscesses, compared with wild-type mice [13]. Rag2 deficient mice, that lack mature $\mathrm{T}$ and $\mathrm{B}$ cells, also did not have altered susceptibility in bloodstream model of S. aureus infection [29]. $\mu \mathrm{MT}$ mice also did not have impaired clearance of $S$. aureus in a model of nasal colonization [30]. Together, these and our current findings demonstrate that $\mu \mathrm{MT}$ mice are selectively susceptible to S. aureus SSTI, and suggest site-specific differences in the role of B cells in defense against S. aureus.

The differences in the resistance to primary infection in $\mu \mathrm{MT}$ and WT mice were observed by day 3 post-infection. The demonstration that larger skin lesions also had increased numbers of bacteria recovered suggests a defect in bacterial clearance. Although the kinetics of bacterial clearance and the role of bacterial burden in the severity of dermonecrotic lesions remains to be fully elucidated [31,32], we and others have demonstrated that large differences in lesion severity (e.g., WT vs. $\mu$ MT mice and strain $923 v s$. $\Delta s b i$ or $\Delta s b i \Delta s p a$ in this study) are accompanied by differences in bacterial burden and 
local inflammatory responses [25,33-35]. While the rapid kinetics suggested a role for nonspecific natural antibodies in defense against $S$. aureus SSTI, our findings that transfer of naïve BALB/c serum did not restore protection in $\mu \mathrm{MT}$ mice, whereas immune serum did, suggested instead for a role of elicited S. aureus-specific antibodies. These findings are consistent with an emerging role for B lymphocytes in early antibacterial defense, either through B cell production of Type I interferon and chemokines [36], and/or the early production of elicited antibodies. These findings have clinical implications for therapeutic passive antibody transfer into patients with B cell immune deficiencies.

$\mathrm{SpA}$ and Sbi are the two major IgG-binding proteins in S. aureus. By using S. aureus mutants lacking spa or sbi, we showed that Sbi, but not SpA, was important in the pathogenesis of primary S. aureus SSTI. The finding that SpA did not play a role in virulence is consistent with the recent findings that deletion of spa impacts skin abscesses, but not dermonecrosis, in a mouse model [37]. SpA also is not required for keratinocyte invasion [38]. These observations, together with reports of SpA being an important virulence factor in mouse models of $S$. aureus pneumonia $[16,17]$ and sepsis [14], underscore the notion that the type of immune response that is protective depends on the site of S. aureus infection. In contrast to SpA, the role of Sbi in virulence is less well documented. A spa/sbi deletion mutant was reported to have attenuated virulence in an epicutaneous model of $S$. aureus infection [39]. In this study we demonstrate the importance of Sbi in virulence and its requirement of B cells/antibody, because differences between the virulence of WT and $\Delta$ sbi $\Delta s p a$ were lost in $\mu \mathrm{MT}$ mice. It is important to note that, although infection with the sbi deletion mutant resulted in fewer bacteria recovered from the skin lesions, complementation of the sbi/spa deletion mutant with $s b i$ did not restore the number of bacteria in the lesions to a level comparable to infection with the WT isolate. These findings raise the possibility that Sbi acts, at least in part, by modulating local inflammatory responses, and not entirely by enhancing bacterial clearance. It is also possible that Sbi and SpA act synertistically to impact bacterial clearance. While we did not define how Sbi confers virulence, we speculate that because Sbi can bind to antibody and complement component C3, it can interfere with antibody/complement-mediated opsonphagocytosis [13]. More work will be needed to better understand the importance of surface-bound vs. secreted Sbi in the pathogenesis of S. aureus infection.

Our observations that spa and / or sbi expression did not affect the development of the antibody response against Hla contrast with recent reports that $\mathrm{SpA}$ interfered with elicited protective antibody responses both in mice and in humans $[14,15]$. In mice, immunization with a $S$. aureus isolate expressing a SpA mutant that could no longer bind to the $\mathrm{Fc} \gamma$ or Fab $\mathrm{V}_{\mathrm{H}} 3$ domains of IgG resulted in superior antibody levels against other $S$. aureus antigens and protection against $S$. aureus sepsis, compared with immunization with WT S. aureus [12-14]. In humans with S. aureus SSTI, Pauli et al. demonstrated that the elicited plasmablast/antibody response is skewed towards SpA [15]. This immunodominant effect of SpA prevented antibody responses against other protective antigens [15]. We reconcile these discrepant findings by hypothesizing that the quality of the elicited antibody response is highly dependent on the primary infectious syndrome. This hypothesis is supported by the fact that bloodstream infection with wild-type $S$. aureus does not elicit protective immunity [14], whereas SSTI does [25]. Therefore, we speculate that neither Sbi nor SpA inhibits antibody responses against Hla or other saeRS-regulated antigens that mediate protection against secondary SSTI [40], but probably do so in other models. The mechanistic details on how SpA inhibits antibody responses in some but not other models of $S$. aureus infection requires further investigation.

In summary, we found that B cell deficient $\mu \mathrm{MT}$ mice exhibited increased susceptibility to S. aureus SSTI that was not reversed by passive transfer of naïve antibody, but was restored by passively transferred immune sera. We also showed that the IgG binding protein Sbi, but not SpA, was important for virulence in S. aureus SSTI in primary infections, and that this virulence required the presence of B cells and/or antibody. Notably, neither Sbi nor SpA interfered with the elicited antibody response or protective immunity against secondary SSTI in BALB/c or C57BL/ 6 mice. Taken together, these findings highlight an important role for B cells, antibodies, and Sbi in innate defense against primary S. aureus SSTI, and the critical role of antibodies in protective immunity. 


\section{Materials and Methods}

\subsection{Bacterial Isolates}

Strain 923 is a previously described USA300 clinical isolate from a patient with a skin infection at the University of Chicago [41]. $\Delta s b i$ is an isogenic sbi deletion mutant of strain 923 generated by allelic recombination using the pMAD vector [42], in which the sbi gene has been replaced by the aad9 gene, encoding spectinomycin resistance. $\Delta s p a$ and $\Delta s b i \Delta s p a$ were generated by phage transduction of a gene encoding tetracycline resistance from 8325-4 $\Delta$ spa, a gift from Mathias Herrmann (University of Saarland) [43], into 923 and $\Delta s b i$, respectively (Table 1). Strain $\Delta s b i \Delta s p a / p s b i$ was constructed by transforming $\Delta$ sbi $\Delta$ spa with a modified pCN48 in which expression of sbi was constitutively driven by the Pspac promoter (Table 1) [44].

Table 1. Oligonucleotides used in this study.

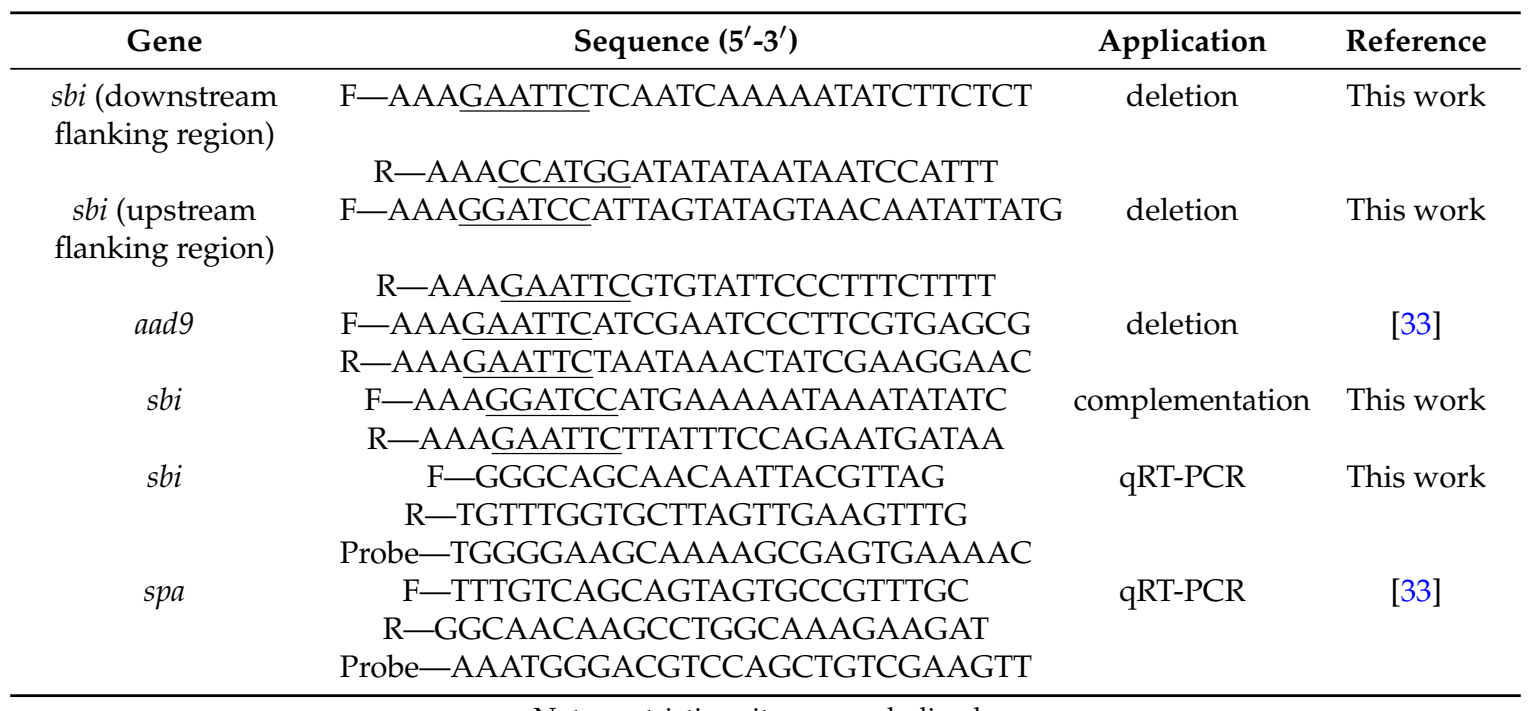

Note: restriction sites are underlined.

\subsection{Expression Analysis by Semiquantitative Reverse-Transcription PCR (qRT-PCR)}

To confirm the deletion of sbi and spa and complementation of sbi, frozen stocks of the bacterial isolates were subcultured onto tryptic soy agar (TSA) overnight at $37^{\circ} \mathrm{C}$. The following evening, one colony was subcultured into $5 \mathrm{~mL}$ tryptic soy broth (TSB) and grown overnight at $37^{\circ} \mathrm{C}$ with shaking (250 rpm). The following morning, the overnight culture was diluted 1:100 in fresh TSB and grown to an $\mathrm{OD}_{600}$ of 0.7 . The bacteria were pelleted by centrifugation and immediately frozen at $-80{ }^{\circ} \mathrm{C}$. For RNA isolation and purification, the pellets were thawed on ice, resuspended in Tris-EDTA, and lysed with the addition of lysostaphin $(200 \mu \mathrm{g} / \mathrm{mL})$ at room temperature for $10 \mathrm{~min}$. Buffer RLT was added and RNA purification was performed using the RNeasy kit with on column DNase treatment (Qiagen). For each sample, $2 \mu \mathrm{g}$ RNA was reverse transcribed using the High Capacity Archive cDNA kit (Applied Biosystems). qRT-PCR was performed using Prime Time ${ }^{\mathrm{TM}}$ qPCR primer probe mixes (Integrated DNA Technologies) for sbi and spa, with gyrB as an endogenous control (Table 1). Relative quantification was calculated by the $\Delta \Delta C_{T}$ method, with expression of each gene in strain 923 as the reference.

\subsection{Mouse Models of Primary and Secondary S. aureus SSTI}

All animal experiments were conducted under protocols approved by the Institutional Animal Care and Use Committee at the University of Chicago. The mouse models of primary and secondary S. aureus SSTI have been described [25,33]. Female BALB/c and C57BL/6 mice were purchased 
from Taconic and were infected at 7 weeks of age. Female $\mu$ MT BALB/c mice (Igh-Jtm1Dhu) were purchased from Taconic or bred at the University of Chicago. Briefly, on the day of inoculation, an overnight culture of $S$. aureus was diluted 1:100 in fresh TSB and grown to an $\mathrm{OD}_{600}$ of 1.8. The bacteria were centrifuged and washed twice in sterile phosphate buffered saline (PBS), after which they were resuspended in PBS to achieve a concentration of $1.5 \times 10^{7} \mathrm{CFU} / 50 \mu \mathrm{L}$. Prior to inoculation, all mice were sedated by administration of ketamine and xylazine. For the model of primary SSTI, the right flank was shaved with clippers and $50 \mu \mathrm{L}$ of S. aureus $\left(1.5 \times 10^{7} \mathrm{CFU}\right)$ was injected subcutaneously. For the model of secondary SSTI, inoculation on the left flank was performed 8 weeks after primary infection. The lesion severity was assessed by digitally measuring the area of dermonecrosis (Adobe Photoshop) for $15 \mathrm{~d}$ after infection.

\subsection{Quantification of Bacteria and Cytokines in the Skin Lesions}

Groups of mice were sacrificed $3 \mathrm{~d}$ after infection by $\mathrm{CO}_{2}$ inhalation. Following sacrifice, the skin lesions were removed aseptically and placed into sterile PBS. The lesions were homogenized and an aliquot of homogenate was removed, serially diluted, and plated on mannitol salt agar for $\mathrm{CFU}$ quantification. Colonies were counted $24 \mathrm{~h}$ after plating. For measurement of cytokines, the homogenate was centrifuged and the supernatant was immediately frozen at $-80^{\circ} \mathrm{C}$. CXCL- 1 and IL-17 were quantified in the supernatants using commercially available ELISA kits (R \& D Systems, Minneapolis, MN, USA).

\subsection{Serum Transfer}

BALB/c mice were sacrificed $14 \mathrm{~d}$ after secondary SSTI with S. aureus strain 923 (or PBS) by $\mathrm{CO}_{2}$ inhalation. Blood was obtained by cardiac puncture and serum was isolated using serum separator tubes (BD Biosciences, Franklin Lakes, NJ, USA). Adoptive transfer of serum was performed by retroorbital injection $(100 \mu \mathrm{L})$ on each of the $2 \mathrm{~d}$ prior to infection.

\subsection{Assessment of Antibody Levels by ELISA}

EIA/RIA 96-well plates (Costar, Corning Inc., Corning, NY, USA) were coated with $5 \mu \mathrm{g} / \mathrm{mL}$ $\alpha$-toxin (Hla) (Sigma-Aldrich, St. Louis, MO, USA). Mouse serum was prepared from whole blood using serum separator tubes (BD Biosciences). The serum was serially diluted in PBS and added to the antigen containing wells. Detection was performed using alkaline phosphatase (AP)-conjugated goat anti-mouse IgG, (1:5000; AffiniPure, Jackson ImmunoResearch, West Grove, PA, USA) and AP substrate p-NitroPhenyl Phosphate (pNPP) (Sigma-Aldrich). Absorbance was measured using a GENios spectrophotometer (Tecan, Männedorf, Switzerland).

\subsection{Data Analysis}

The size of the skin lesions were compared using student's $t$ test or one-way ANOVA with Tukey's post test, where appropriate. The bacterial CFU and cytokine levels in the skin lesions and anti-Hla levels were compared using student's $t$ test. The expression of sbi and spa by qRT-PCR were compared using one-way ANOVA with Tukey's post test. All statistical analyses were performed using GraphPad Prism. $p<0.05$ was considered statistically significant.

Acknowledgments: This work was funded by the Department of Pediatrics at the University of Chicago and the National Institute of Allergy and Infectious Diseases (AI076596 to CPM). The authors would like to thank Brian LM Cheng for expert technical assistance with the cloning of the sbi gene.

Author Contributions: Fan Zhao, Anita S. Chong and Christopher P. Montgomery conceived and designed the experiments; Fan Zhao and Christopher P. Montgomery performed the experiments; Fan Zhao, Anita S. Chong and Christopher P. Montgomery analyzed the data; Anita S. Chong and Christopher P. Montgomery wrote the paper.

Conflicts of Interest: The authors have no conflicts of interest to declare. 


\section{References}

1. David, M.Z.; Daum, R.S. Community-associated methicillin-resistant staphylococcus aureus: Epidemiology and clinical consequences of an emerging epidemic. Clin. Microbiol. Rev. 2010, 23, 616-687. [CrossRef] [PubMed]

2. Miller, L.G.; Eells, S.J.; David, M.Z.; Ortiz, N.; Taylor, A.R.; Kumar, N.; Cruz, D.; Boyle-Vavra, S.; Daum, R.S. Staphylococcus aureus skin infection recurrences among household members: An examination of host, behavioral, and pathogen-level predictors. Clin. Infect. Dis. 2015, 60, 753-763. [CrossRef] [PubMed]

3. Milner, J.D.; Brenchley, J.M.; Laurence, A.; Freeman, A.F.; Hill, B.J.; Elias, K.M.; Kanno, Y.; Spalding, C.; Elloumi, H.Z.; Paulson, M.L.; et al. Impaired t(h)17 cell differentiation in subjects with autosomal dominant hyper-ige syndrome. Nature 2008, 452, 773-776. [CrossRef] [PubMed]

4. Vyas, K.J.; Shadyab, A.H.; Lin, C.D.; Crum-Cianflone, N.F. Trends and factors associated with initial and recurrent methicillin-resistant staphylococcus aureus (mrsa) skin and soft-tissue infections among hiv-infected persons: An 18-year study. J. Int. Assoc. Prov. AIDS Care 2014, 13, 206-213. [CrossRef] [PubMed]

5. Hemmige, V.; McNulty, M.; Silverman, E.; David, M.Z. Predictors of skin and soft tissue infections in hiv-infected outpatients in the community-associated methicillin-resistant staphylococcus aureus era. Eur. J. Clin. Microbiol. Infect. Dis. 2015, 34, 339-347. [CrossRef] [PubMed]

6. Hausser, C.; Virelizier, J.L.; Buriot, D.; Griscelli, C. Common variable hypogammaglobulinemia in children. Clinical and immunologic observations in 30 patients. Am. J. Dis. Child 1983, 137, 833-837. [CrossRef] [PubMed]

7. Hermaszewski, R.A.; Webster, A.D. Primary hypogammaglobulinaemia: A survey of clinical manifestations and complications. Q. J. Med. 1993, 86, 31-42. [PubMed]

8. Verkaik, N.J.; Boelens, H.A.; de Vogel, C.P.; Tavakol, M.; Bode, L.G.; Verbrugh, H.A.; van Belkum, A.; van Wamel, W.J. Heterogeneity of the humoral immune response following staphylococcus aureus bacteremia. Eur. J. Clin. Microbiol. Infect. Dis. 2010, 29, 509-518. [CrossRef] [PubMed]

9. Thomsen, I.P.; Dumont, A.L.; James, D.B.; Yoong, P.; Saville, B.R.; Soper, N.; Torres, V.J.; Creech, C.B. Children with invasive staphylococcus aureus disease exhibit a potently neutralizing antibody response to the cytotoxin lukab. Infect. Immun. 2014, 82, 1234-1242. [CrossRef] [PubMed]

10. Fritz, S.A.; Tiemann, K.M.; Hogan, P.G.; Epplin, E.K.; Rodriguez, M.; Al-Zubeidi, D.N.; Bubeck Wardenburg, J.; Hunstad, D.A. A serologic correlate of protective immunity against community-onset staphylococcus aureus infection. Clin. Infect. Dis. 2013, 56, 1554-1561. [CrossRef] [PubMed]

11. Goodyear, C.S.; Narita, M.; Silverman, G.J. In vivo vl-targeted activation-induced apoptotic supraclonal deletion by a microbial b cell toxin. J. Immunol. 2004, 172, 2870-2877. [CrossRef] [PubMed]

12. Kim, H.K.; Cheng, A.G.; Kim, H.Y.; Missiakas, D.M.; Schneewind, O. Nontoxigenic protein a vaccine for methicillin-resistant staphylococcus aureus infections in mice. J. Exp. Med. 2010, 207, 1863-1870. [CrossRef] [PubMed]

13. Falugi, F.; Kim, H.K.; Missiakas, D.M.; Schneewind, O. Role of protein a in the evasion of host adaptive immune responses by staphylococcus aureus. MBio 2013, 4, e00575-13. [CrossRef] [PubMed]

14. Kim, H.K.; Kim, H.Y.; Schneewind, O.; Missiakas, D. Identifying protective antigens of staphylococcus aureus, a pathogen that suppresses host immune responses. FASEB J. 2011, 25, 3605-3612. [CrossRef] [PubMed]

15. Pauli, N.T.; Kim, H.K.; Falugi, F.; Huang, M.; Dulac, J.; Dunand, C.H.; Zheng, N.Y.; Kaur, K.; Andrews, S.F.; Huang, Y.; et al. Staphylococcus aureus infection induces protein a-mediated immune evasion in humans. J. Exp. Med. 2014, 211, 2331-2339. [CrossRef] [PubMed]

16. Gomez, M.I.; Lee, A.; Reddy, B.; Muir, A.; Soong, G.; Pitt, A.; Cheung, A.; Prince, A. Staphylococcus aureus protein a induces airway epithelial inflammatory responses by activating tnfr1. Nat. Med. 2004, 10, 842-848. [CrossRef] [PubMed]

17. Bubeck Wardenburg, J.; Patel, R.J.; Schneewind, O. Surface proteins and exotoxins are required for the pathogenesis of staphylococcus aureus pneumonia. Infect. Immun. 2007, 75, 1040-1044. [CrossRef] [PubMed]

18. Cheng, A.G.; Kim, H.K.; Burts, M.L.; Krausz, T.; Schneewind, O.; Missiakas, D.M. Genetic requirements for staphylococcus aureus abscess formation and persistence in host tissues. FASEB J. 2009, 23, 3393-3404. [CrossRef] [PubMed] 
19. Atkins, K.L.; Burman, J.D.; Chamberlain, E.S.; Cooper, J.E.; Poutrel, B.; Bagby, S.; Jenkins, A.T.; Feil, E.J.; van den Elsen, J.M. S. Aureus igg-binding proteins spa and sbi: Host specificity and mechanisms of immune complex formation. Mol. Immunol. 2008, 45, 1600-1611. [CrossRef] [PubMed]

20. Smith, E.J.; Visai, L.; Kerrigan, S.W.; Speziale, P.; Foster, T.J. The sbi protein is a multifunctional immune evasion factor of staphylococcus aureus. Infect. Immun. 2011, 79, 3801-3809. [CrossRef] [PubMed]

21. Foster, T.J. Immune evasion by staphylococci. Nat. Rev. Microbiol. 2005, 3, 948-958. [CrossRef] [PubMed]

22. Burman, J.D.; Leung, E.; Atkins, K.L.; O'Seaghdha, M.N.; Lango, L.; Bernado, P.; Bagby, S.; Svergun, D.I.; Foster, T.J.; Isenman, D.E.; et al. Interaction of human complement with sbi, a staphylococcal immunoglobulin-binding protein: Indications of a novel mechanism of complement evasion by staphylococcus aureus. J. Biol. Chem. 2008, 283, 17579-17593. [CrossRef] [PubMed]

23. Clark, E.A.; Crennell, S.; Upadhyay, A.; Zozulya, A.V.; Mackay, J.D.; Svergun, D.I.; Bagby, S.; van den Elsen, J.M. A structural basis for staphylococcal complement subversion: X-ray structure of the complement-binding domain of staphylococcus aureus protein sbi in complex with ligand c3d. Mol. Immunol. 2011, 48, 452-462. [CrossRef] [PubMed]

24. Koch, T.K.; Reuter, M.; Barthel, D.; Bohm, S.; van den Elsen, J.; Kraiczy, P.; Zipfel, P.F.; Skerka, C. Staphylococcus aureus proteins sbi and efb recruit human plasmin to degrade complement c3 and c3b. PLoS ONE 2012, 7, e47638. [CrossRef] [PubMed]

25. Montgomery, C.P.; Daniels, M.; Zhao, F.; Alegre, M.L.; Chong, A.S.; Daum, R.S. Protective immunity against recurrent staphylococcus aureus skin infection requires antibody and interleukin-17a. Infect. Immun. 2014, 82, 2125-2134. [CrossRef] [PubMed]

26. Bubeck Wardenburg, J.; Schneewind, O. Vaccine protection against staphylococcus aureus pneumonia. J. Exp. Med. 2008, 205, 287-294. [CrossRef] [PubMed]

27. Kennedy, A.D.; Bubeck Wardenburg, J.; Gardner, D.J.; Long, D.; Whitney, A.R.; Braughton, K.R.; Schneewind, O.; DeLeo, F.R. Targeting of alpha-hemolysin by active or passive immunization decreases severity of usa300 skin infection in a mouse model. J. Infect. Dis. 2010, 202, 1050-1058. [CrossRef] [PubMed]

28. Spellberg, B.; Ibrahim, A.S.; Yeaman, M.R.; Lin, L.; Fu, Y.; Avanesian, V.; Bayer, A.S.; Filler, S.G.; Lipke, P.; Otoo, H.; et al. The antifungal vaccine derived from the recombinant $\mathrm{n}$ terminus of als $3 \mathrm{p}$ protects mice against the bacterium staphylococcus aureus. Infect. Immun. 2008, 76, 4574-4580. [CrossRef] [PubMed]

29. Schmaler, M.; Jann, N.J.; Ferracin, F.; Landmann, R. T and b cells are not required for clearing staphylococcus aureus in systemic infection despite a strong tlr2-myd88-dependent $t$ cell activation. J. Immunol. 2011, 186, 443-452. [CrossRef] [PubMed]

30. Archer, N.K.; Harro, J.M.; Shirtliff, M.E. Clearance of staphylococcus aureus nasal carriage is t cell dependent and mediated through interleukin-17a expression and neutrophil influx. Infect. Immun. 2013, 81, 2070-2075. [CrossRef] [PubMed]

31. Montgomery, C.P.; Daniels, M.D.; Zhao, F.; Spellberg, B.; Chong, A.S.; Daum, R.S. Local inflammation exacerbates the severity of staphylococcus aureus skin infection. PLoS ONE 2013, 8, e69508. [CrossRef] [PubMed]

32. Sampedro, G.R.; DeDent, A.C.; Becker, R.E.; Berube, B.J.; Gebhardt, M.J.; Cao, H.; Bubeck Wardenburg, J. Targeting staphylococcus aureus alpha-toxin as a novel approach to reduce severity of recurrent skin and soft-tissue infections. J. Infect. Dis. 2014, 210, 1012-1018. [CrossRef] [PubMed]

33. Montgomery, C.P.; Boyle-Vavra, S.; Daum, R.S. Importance of the global regulators agr and saers in the pathogenesis of ca-mrsa usa300 infection. PLoS ONE 2010, 5, e15177. [CrossRef] [PubMed]

34. Cho, J.S.; Pietras, E.M.; Garcia, N.C.; Ramos, R.I.; Farzam, D.M.; Monroe, H.R.; Magorien, J.E.; Blauvelt, A.; Kolls, J.K.; Cheung, A.L.; et al. Il-17 is essential for host defense against cutaneous staphylococcus aureus infection in mice. J. Clin. Investig. 2010, 120, 1762-1773. [CrossRef] [PubMed]

35. Miller, L.S.; O'Connell, R.M.; Gutierrez, M.A.; Pietras, E.M.; Shahangian, A.; Gross, C.E.; Thirumala, A.; Cheung, A.L.; Cheng, G.; Modlin, R.L. Myd88 mediates neutrophil recruitment initiated by il-1r but not tlr2 activation in immunity against staphylococcus aureus. Immunity 2006, 24, 79-91. [CrossRef] [PubMed]

36. Kelly-Scumpia, K.M.; Scumpia, P.O.; Weinstein, J.S.; Delano, M.J.; Cuenca, A.G.; Nacionales, D.C.; Wynn, J.L.; Lee, P.Y.; Kumagai, Y.; Efron, P.A.; et al. B cells enhance early innate immune responses during bacterial sepsis. J. Exp. Med. 2011, 208, 1673-1682. [CrossRef] [PubMed]

37. Kwiecinski, J.; Jin, T.; Josefsson, E. Surface proteins of staphylococcus aureus play an important role in experimental skin infection. Apmis 2014, 122, 1240-1250. [CrossRef] [PubMed] 
38. Soong, G.; Chun, J.; Parker, D.; Prince, A. Staphylococcus aureus activation of caspase 1/calpain signaling mediates invasion through human keratinocytes. J. Infect. Dis. 2012, 205, 1571-1579. [CrossRef] [PubMed]

39. Prabhakara, R.; Foreman, O.; De Pascalis, R.; Lee, G.M.; Plaut, R.D.; Kim, S.Y.; Stibitz, S.; Elkins, K.L.; Merkel, T.J. Epicutaneous model of community-acquired staphylococcus aureus skin infections. Infect. Immun. 2013, 81, 1306-1315. [CrossRef] [PubMed]

40. Zhao, F.; Cheng, B.L.; Boyle-Vavra, S.; Alegre, M.L.; Daum, R.S.; Chong, A.S.; Montgomery, C.P. Proteomic identification of saers-dependent targets critical for protective humoral immunity against staphylococcus aureus skin infection. Infect. Immun. 2015, 83, 3712-3721. [CrossRef] [PubMed]

41. Montgomery, C.P.; Boyle-Vavra, S.; Adem, P.V.; Lee, J.C.; Husain, A.N.; Clasen, J.; Daum, R.S. Comparison of virulence in community-associated methicillin-resistant staphylococcus aureus pulsotypes usa300 and usa400 in a rat model of pneumonia. J. Infect. Dis. 2008, 198, 561-570. [CrossRef] [PubMed]

42. Arnaud, M.; Chastanet, A.; Debarbouille, M. New vector for efficient allelic replacement in naturally nontransformable, low-gc-content, gram-positive bacteria. Appl. Environ. Microbiol. 2004, 70, 6887-6891. [CrossRef] [PubMed]

43. Hartleib, J.; Kohler, N.; Dickinson, R.B.; Chhatwal, G.S.; Sixma, J.J.; Hartford, O.M.; Foster, T.J.; Peters, G.; Kehrel, B.E.; Herrmann, M. Protein a is the von willebrand factor binding protein on staphylococcus aureus. Blood 2000, 96, 2149-2156. [PubMed]

44. Charpentier, E.; Anton, A.I.; Barry, P.; Alfonso, B.; Fang, Y.; Novick, R.P. Novel cassette-based shuttle vector system for gram-positive bacteria. Appl. Environ. Microbiol. 2004, 70, 6076-6085. [CrossRef] [PubMed]

(C) 2016 by the authors; licensee MDPI, Basel, Switzerland. This article is an open access article distributed under the terms and conditions of the Creative Commons by Attribution (CC-BY) license (http:/ / creativecommons.org/licenses/by/4.0/). 